\title{
The M7.1 May 26, 2003 off-shore Miyagi Prefecture Earthquake in northeast Japan: Source process and aftershock distribution of an intra-slab event
}

\author{
Tomomi Okada and Akira Hasegawa \\ Research Center for Prediction of Earthquakes and Volcanic Eruptions, Graduate School of Science, Tohoku University, Sendai 980-8578, Japan
}

(Received September 30, 2003; Revised December 27, 2003; Accepted December 27, 2003)

\begin{abstract}
A M7.1 intra-slab earthquake occurred on May 26, 2003 at a depth of $68 \mathrm{~km}$ off-shore Miyagi Prefecture, northeastern Japan. The epicenter of this event was located about $80 \mathrm{~km}$ NNE from the epicenter of the 1978 offshore Miyagi earthquake with magnitude of 7.4, whose possible recurrence in near future is a source of concern. We relocated the 2003 M7.1 event and its aftershocks by the homogeneous station method. Aftershocks are distributed along a plane dipping steeply to the WNW, which coincides with one of the nodal planes of the moment tensor solution. They are distributed within both the subducting oceanic crust and the mantle of the slab. The mainshock is located near the center of the aftershock zone and probably occurred near the bottom of the oceanic crust. We also determined the slip distribution of the 2003 M7.1 event by a waveform inversion method based on the empirical Green's function. We inverted broad-band waveform data observed at stations with epicentral distance less than about $100 \mathrm{~km}$. Results show that the spatial extent of the rupture area is almost consistent with that of the aftershock area. There exist two areas where large amount of slip occurred (asperities). One is located along the northeastern edge of the rupture area and the other is located in the southwestern portion. Aftershock activity is low within those asperities.
\end{abstract}

Key words: The 2003 off-shore Miyagi earthquake, intra-slab event, hypocenter distribution, source process, double seismic zone, 1978 off-shore Miyagi inter-plate earthquake.

\section{Introduction}

A large earthquake occurred on May 26, 2003 at a depth of $68 \mathrm{~km}$ off-shore Miyagi Prefecture, northeastern Japan. (Fig. 1). This event (hereafter we call the 2003 off-shore Miyagi earthquake) caused damage to some buildings, e.g. pillars of the elevated railroad of Shinkanken (super express train), in wide areas of northern Tohoku. The epicenter of this event was located at about $80 \mathrm{~km}$ NNE from the epicenter of the 1978 off-shore Miyagi earthquake with M7.4. The 1978 off-shore Miyagi earthquake was a typical interplate earthquake east of Miyagi prefecture. On Feb. 20, 1978, about 5 months before the 1978 off-shore Miyagi earthquake, an intraslab event with M6.7 occurred $60 \mathrm{~km}$ NE from the epicenter of the 1978 off-shore Miyagi earthquake. Both the 2003 M7.1 off-shore Miyagi earthquake and the 1978 M6.7 event are located around the asperity of the M7.4 1978 off-shore Miyagi earthquake (Yamanaka and Kikuchi, 2002) along the plate boundary. Investigations of these events are important to understand the interaction between the interplate earthquake and the intra-slab earthquake.

In the present paper, we investigate the detailed distribution of aftershocks of the 2003 off-shore Miyagi earthquake and that of the background seismicity, and then compare them with the slip distribution of the earthquake.

Copy right(C) The Society of Geomagnetism and Earth, Planetary and Space Science (SGEPSS); The Seismological Society of Japan; The Volcanological Society of Japan; The Geodetic Society of Japan; The Japanese Society for Planetary Sciences.

\section{Hypocenter Relocation}

First, we precisely relocated hypocenters of the 2003 offshore Miyagi earthquake and its aftershocks. We adopted the homogeneous station method (Ansel and Smith, 1975) to avoid the effect of inhomogeneous structure of the crust and upper mantle, which will appear when different station sets are used for hypocenter locations. We used data from ten stations for $P$-wave arrival times and five stations for $S$-wave arrival times (Fig. 2). The seismic velocity model routinely used in the Tohoku University seismic network (Hasegawa et al., 1978) was adopted in the calculation of travel times.

Figure 3 shows hypocenters of the 2003 off-shore Miyagi earthquake and its aftershocks thus relocated. Relocated aftershocks are distributed along a steeply dipping plane. Its dip angle seems to be larger in the shallow part of the aftershock area. The mainshock is located near the center of the aftershock zone. We compared this aftershock distribution with the upper boundary of the subducting slab estimated from phase-converted waves (Zhao et al., 1997). The aftershocks are distributed just below the upper boundary of the slab. A two-layer slab model in which the upper layer has a $P$-wave velocity $6 \%$ lower than the overriding mantle was proposed (Matsuzawa et al., 1986). This low-velocity upper layer corresponds to the subducted oceanic crust, and events in the upper seismic plane occur within this thin (about 5 to $10 \mathrm{~km}$ ) oceanic crust on the surface of the subducted slab. The present aftershocks seem to be located within both the subducting oceanic crust and the mantle of the slab. The mainshock is located about $8 \mathrm{~km}$ below the estimated plate boundary (Fig. 3). This supports that the initial rupture of 


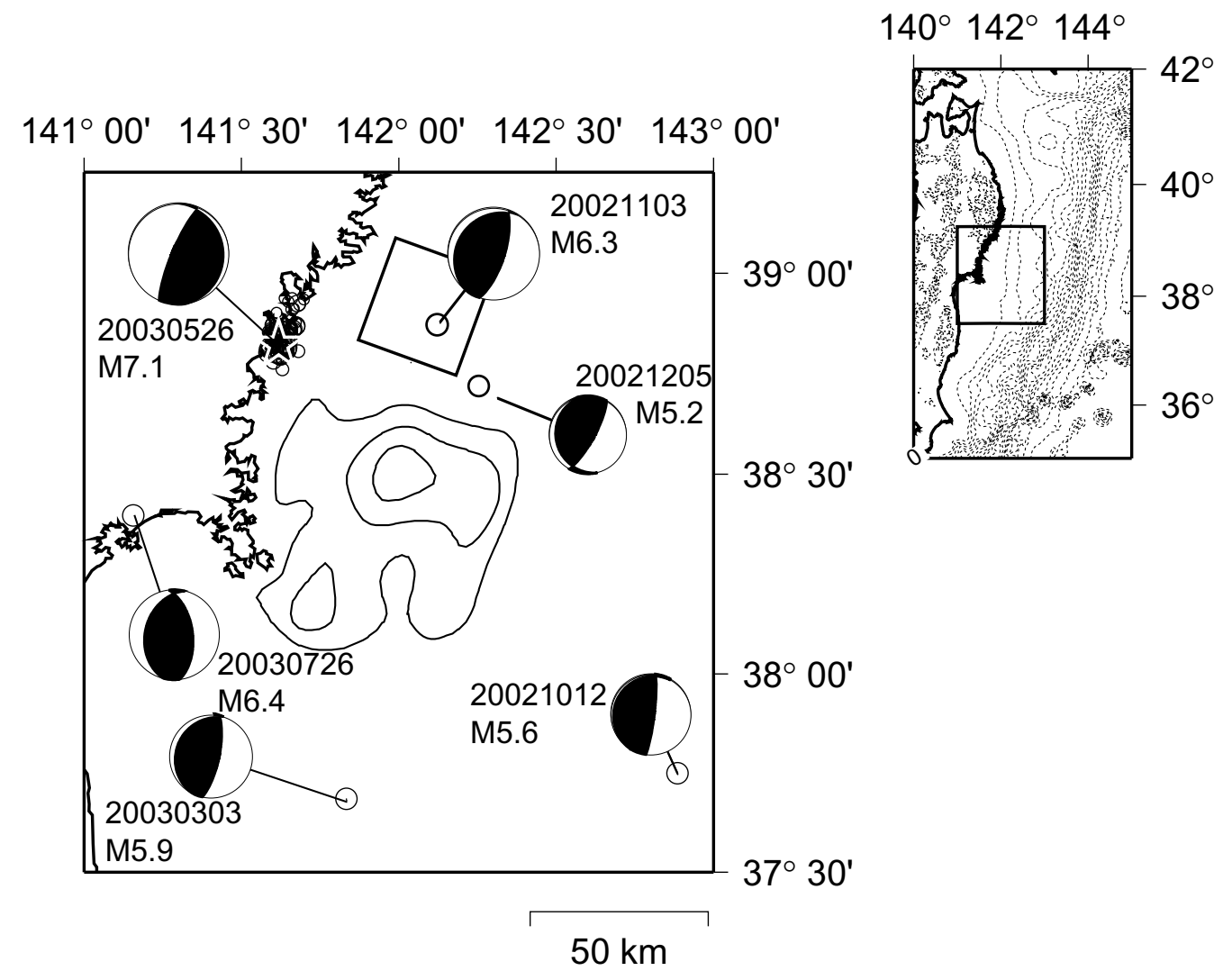

Fig. 1. Epicenter distribution of 2003 M7.1 off-shore Miyagi earthquakes and other major earthquakes that occurred recently near the focal area of the 1978 off-shore Miyagi earthquake (M7.4). Moment tensor solutions for these events are also shown. Square denotes quasi-static slip area following the Nov. 3, 2002 M6.3 event estimated from GPS observation (Miura et al., 2003). Contour denotes the rupture area of the 1978 M7.4 off-shore Miyagi earthquake obtained by waveform inversion (Yamanaka and Kikuchi, 2002). Contour interval is $1 \mathrm{~m}$. Contour in the insert map denotes the bathymetry at an interval of $0.5 \mathrm{~km}$.

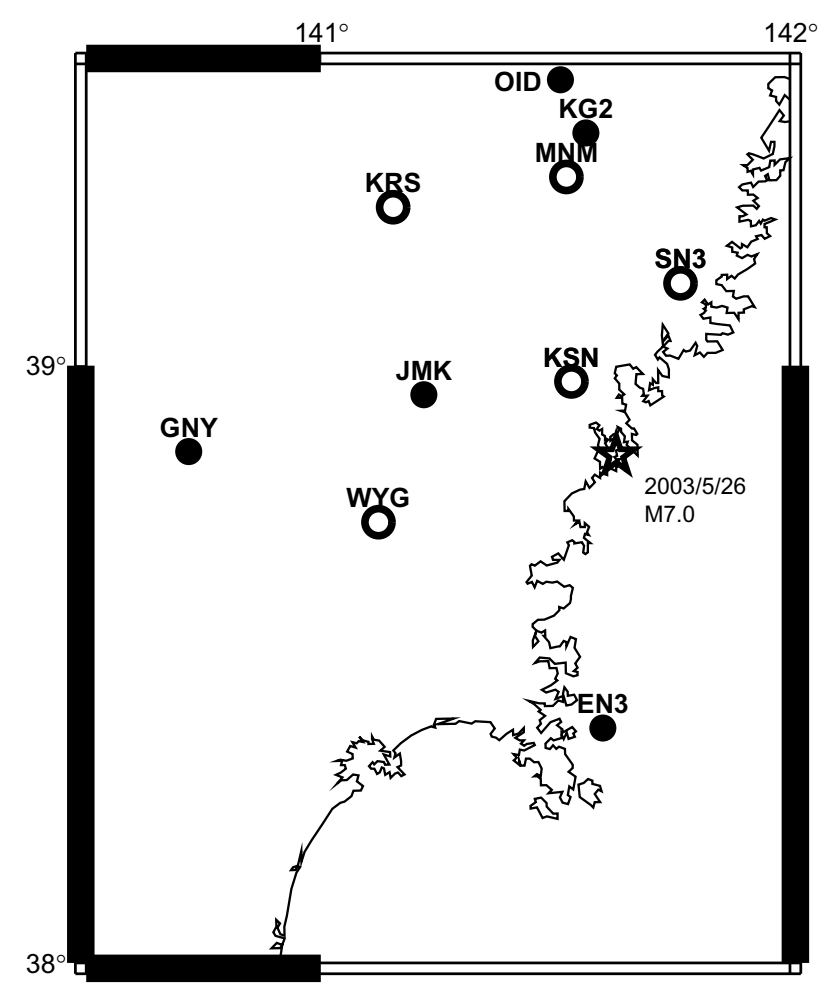

Fig. 2. Locations of stations used in hypocenter relocations by the homogeneous station method. $S$-wave arrival times at stations denoted by solid circles and $P$-wave arrival times at all the stations shown are used. the present M7.1 event occurred near the boundary between the oceanic crust and the mantle.

A moment tensor solution of this event is also shown in Fig. 1. We determined moment tensors using regional broadband seismograms (Okada et al., 2001b, 2003b). The obtained moment tensor is a down-dip compression-type solution with a steeply westward dipping plane, which is consistent with the aftershock distribution. The non-double-couple component is quite small $(<10 \%)$ compared to doublecouple component. Note that this non-double-couple component also includes a part of artifacts made by using the 1D velocity model. We also determined a fault plane solution from first $P$-wave polarity data. The obtained fault plane solution is down-dip compression-type which is similar to the moment tensor solution.

\section{Source Processes}

We determined moment release distribution on the fault planes of the 2003 M7.1 event by a waveform inversion method (Okada et al., 2001a) based on the concept of the empirical Green's function method (e.g. Hartzell, 1978; Mori and Hartzell, 1990; Flecther and Spudich, 1998). Observed waveforms are inverted to determine the source time function of each grid distributed on the fault plane. In the inversion, we used the multiple time window method (Hartzell and Heaton, 1983). We corrected the difference in rise time between the target earthquake and a smaller event used as 
(a)

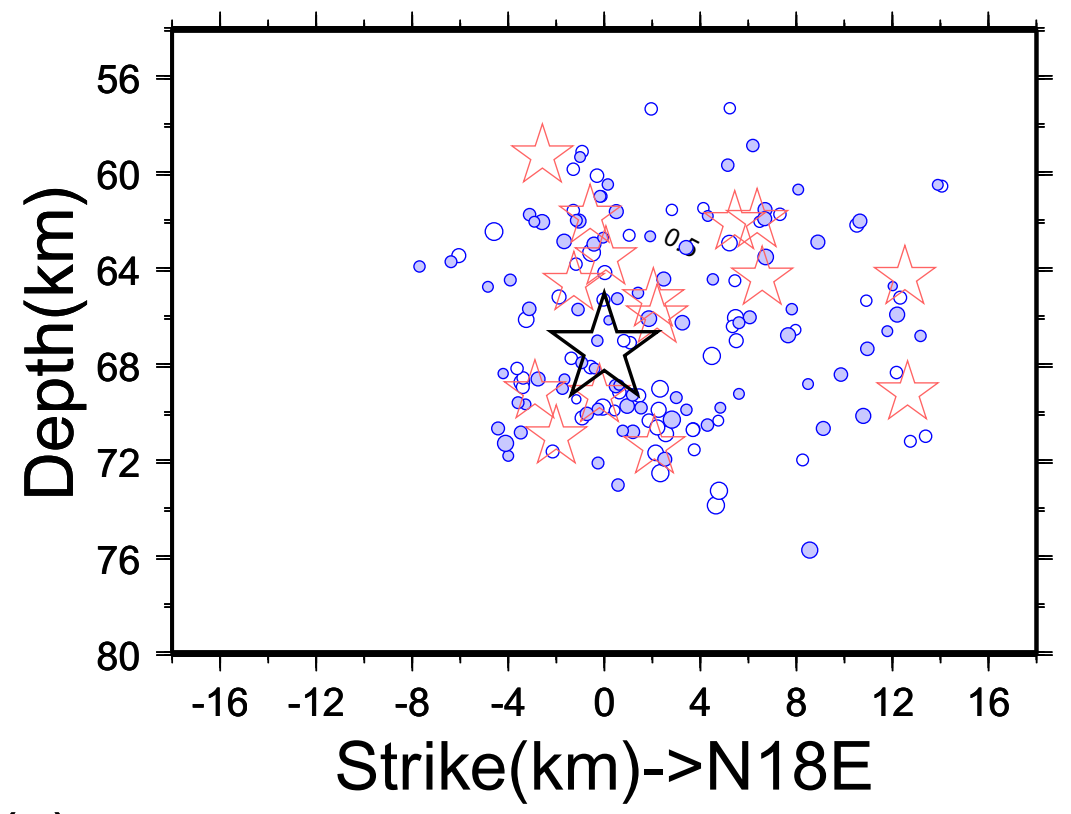

(b)

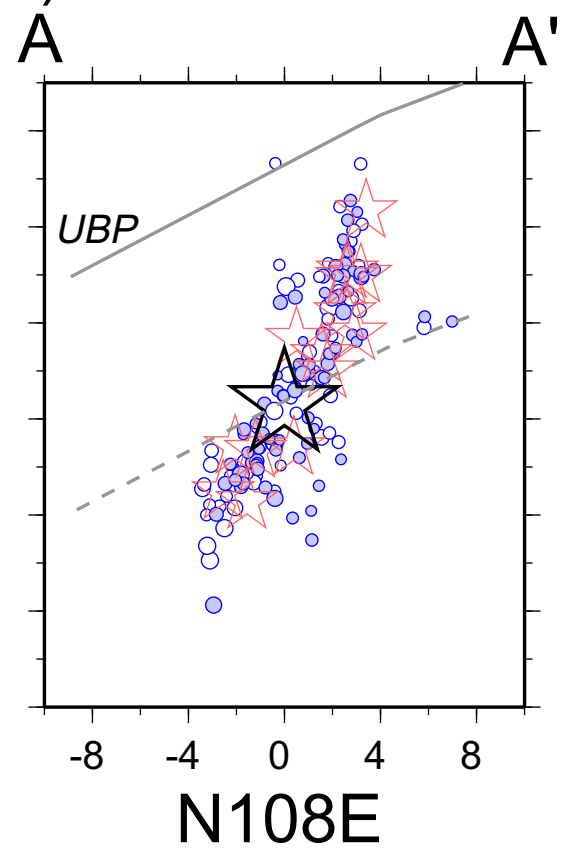

(c) $141^{\circ} 30^{\prime}$ $142^{\circ} 00^{\prime}$

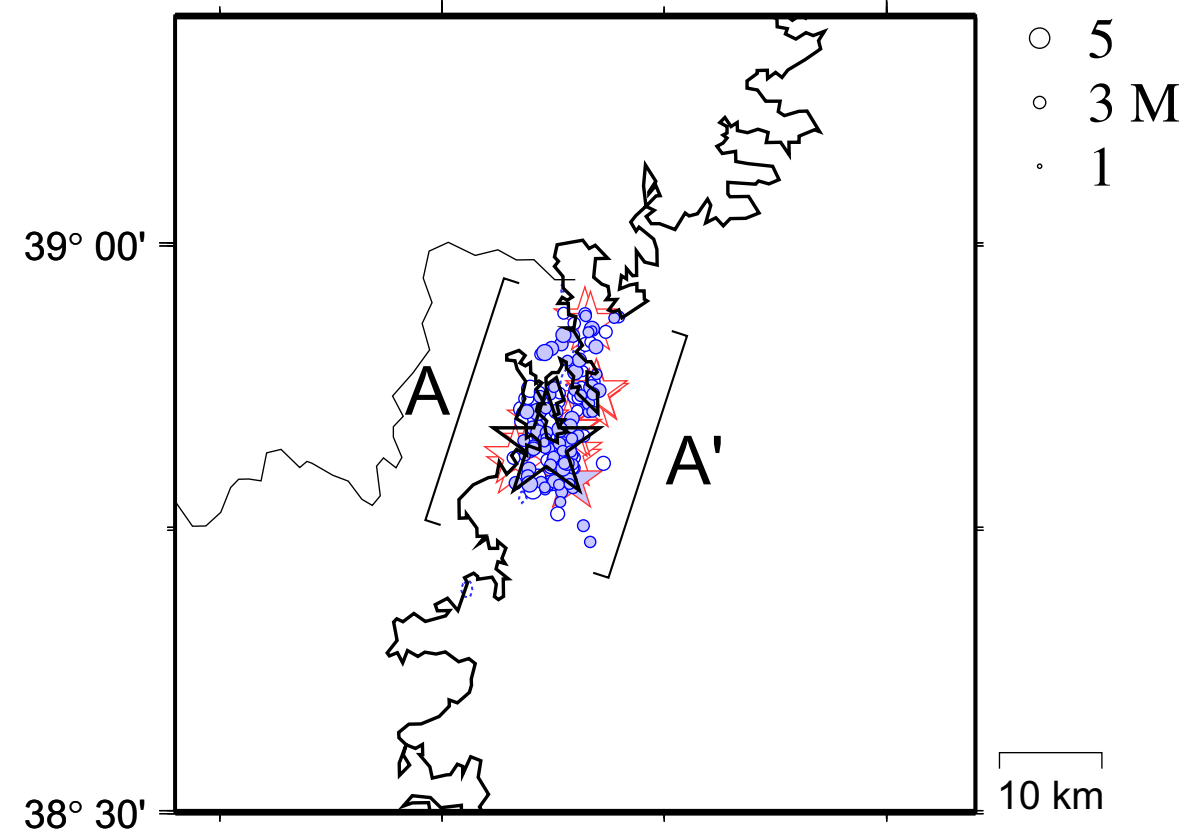

Fig. 3. Aftershock distribution within 1 day of the main shock occurrence. Main shock and aftershocks with magnitude greater than 4.5 are shown by a large star, medium stars, respectively. (a) Vertical cross section along the strike. (b) Vertical cross section perpendicular to the strike. Bold line denotes the upper boundary of the slab estimated by Zhao et al. (1997) (c) Epicenter distribution.

empirical Green's function and the perturbation of rupture velocity is represented by the multiple time window method. Slip direction of the target earthquake was assumed to be the same as that of the empirical Green's function event over the whole fault plane. Relative source time function for each grid is assumed to be expressed as a sum of isoscale triangles with a base of $t_{\text {rise }}$. The interval between the triangles is a half of duration $t_{\text {rise }}$. Thus, unknown parameters are these heights of triangles. To stabilize the solution, we add smoothing constraints in the inversion. The equation to be solved by the inversion is

$$
\left(\begin{array}{c}
A \\
s \cdot D
\end{array}\right) x=\left(\begin{array}{l}
b \\
0
\end{array}\right),
$$

where $A$ is the matrix of the Green's function, $b$ is observed seismograms (data), $x$ is amplitude of relative moment release (i.e. the heights of triangles) for each time window of each grid, $D$ is a first-degree differential operator for time and space domains, and $s$ is a constant to weight the smoothing. In this case, we use 0.2 as the value of smoothing. 
(a)

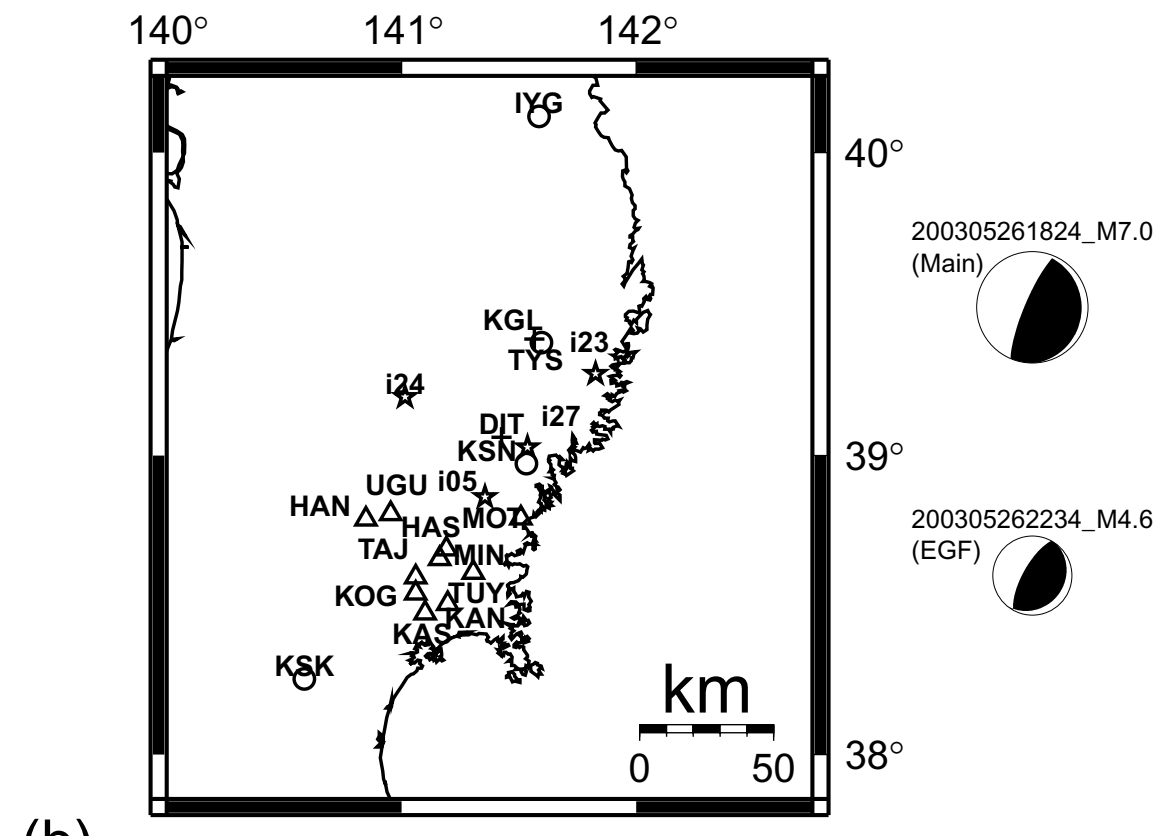

(b)

\begin{tabular}{llllllllllll}
0 & 2 & 4 & 6 & 8 & 10 & 12 & 14 & 16 & 18 & 20 & 22 \\
\hline
\end{tabular}

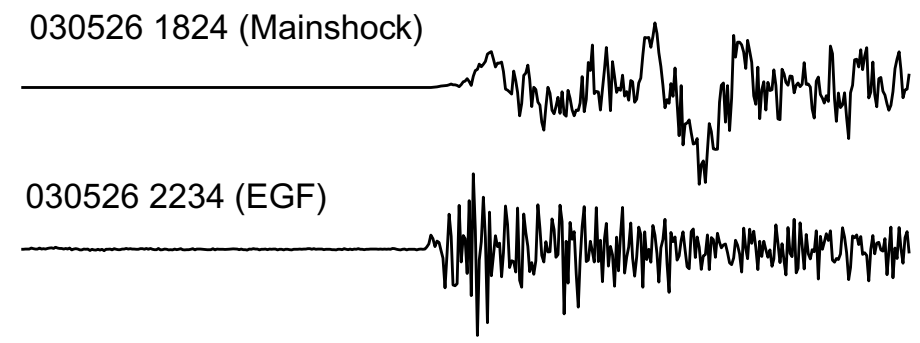

Fig. 4. (a) Locations of station used in the waveform inversion. Crosses denote the stations of Tohoku University where velocity-type strong motion meters are deployed. Circles, stars and triangles denote the stations of F-net, Kik-net and Miyagi Prefecture, respectively. Moment tensor solution of the mainshock and an aftershock used as EGF are also shown. (b) Examples of waveforms observed at station IYG from the mainshock and an aftershock used as EGF. Vertical-component seismograms in a length of 22 seconds starting 10 seconds before the first $P$ wave arrival are shown.

The rupture front is assumed to propagate circularly with a velocity of $80 \%$ of $S$-wave velocity at the source depth. We used $t_{\text {rise }}$ of $0.75 \mathrm{sec}$ to make the observed and synthetic waveforms fit well. The fault plane was assumed as a highangle westward dipping planar plane (Strike: N18E, Dip: 60) referring to the moment tensor solution (Fig. 1) and aftershock distribution. We used a a grid net of 156 points spaced $3 \mathrm{~km}$, which covers spatial extent of the aftershock area, on the fault plane. An aftershock (5/26/2003 22:34 M4.6), which has almost the same mechanism as that of the mainshock and whose waveforms are observed in good $\mathrm{S} / \mathrm{N}$, was selected as the empirical Green's function. Note that we didn't correct the amplitude of the EGF depending on the location of the grid point in this analysis. We used the seismic wave velocity model routinely used in the Tohoku University seismic network (Hasegawa et al., 1978) for calculating the ray paths.

Waveform data used were from the Tohoku University's seismic network, the Kik-net, K-net, and F-net of the National Institute for Earth Sciences and Disaster Preventions. Figure 4 shows the locations of stations used in the present analysis. We chose these stations because of waveform data of the EGF in good S/N. Data used are of strong motion accelerometers (KiK-net, K-net) or velocity meter (Tohoku Univ., F-net). We also used waveform data from the strong motion seismographs (A/D: 20 bits $( \pm 2 \mathrm{G})$, sampling freq.: $100 \mathrm{~Hz}$ ) of Seismic Intensity Network of Miyagi Prefecture. Waveform data recorded at these stations were first low-pass filtered with a cut off frequency of $1 \mathrm{~Hz}$ and, then resampled at a sampling rate of $20 \mathrm{~Hz}$. We used 15 second, verticalcomponent seismograms starting 3 seconds before the first $P$ wave arrival.

Figure 5 shows the obtained moment release distribution of the 2003 off-shore Miyagi earthquake. Spatial extent of the rupture area is about $20 \times 20 \mathrm{~km}^{2}$, which is consistent with the spatial extent of the aftershock area. Northward ex- 


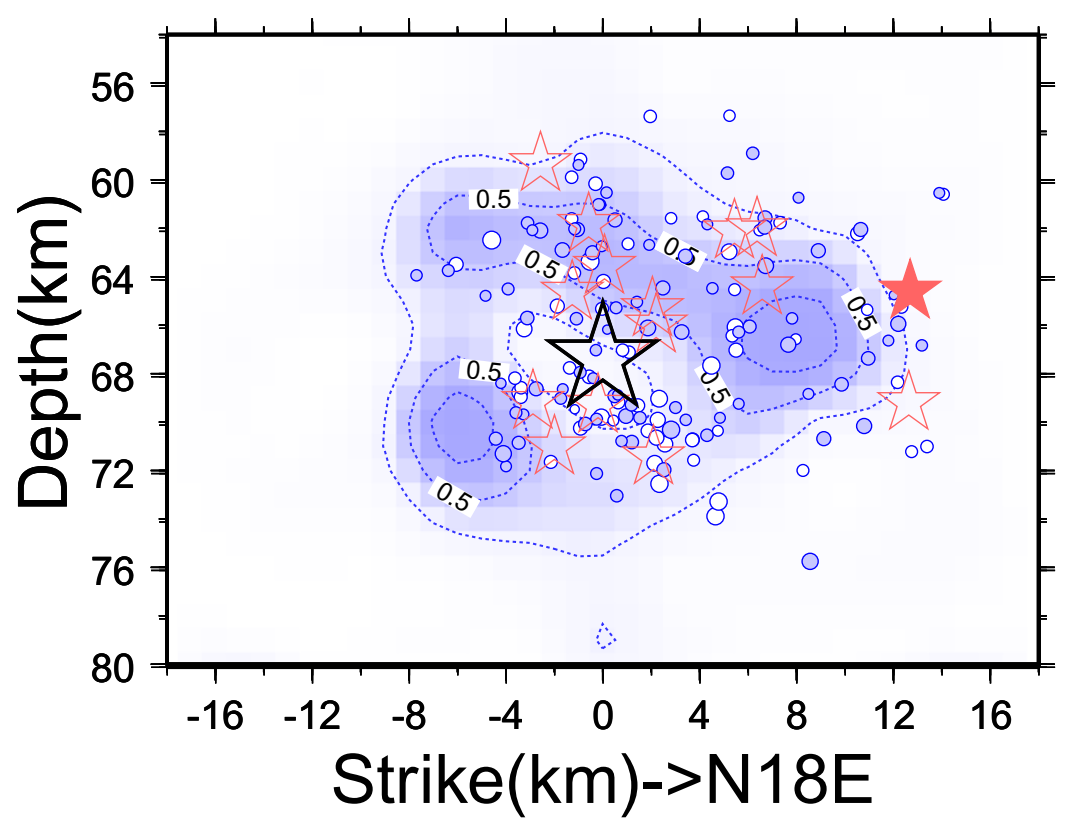

Fig. 5. Slip distribution of the 2003 M7.1 earthquake. Values normalized by the peak value $(3 \mathrm{~m})$ are shown. Broken bold line shows the aftershock alignment. Aftershocks shown in Fig. 3 are also shown. Solid medium star denotes an aftershock used as EGF.

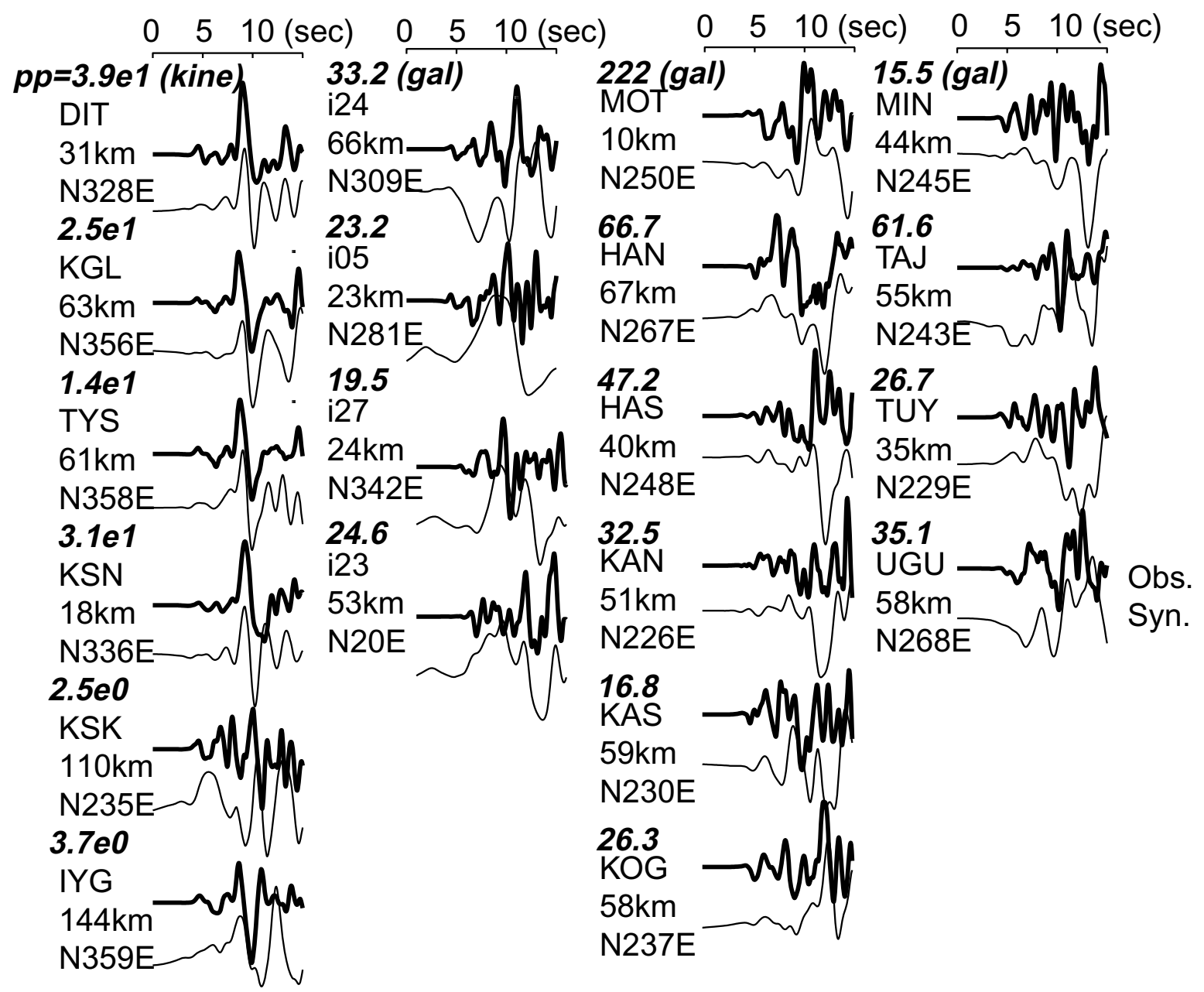

Fig. 6. Comparison of the observed waveforms (upper traces) with the synthetic ones (lower traces). Delta $(\mathrm{km})$ and azimuth of each station is also shown. 


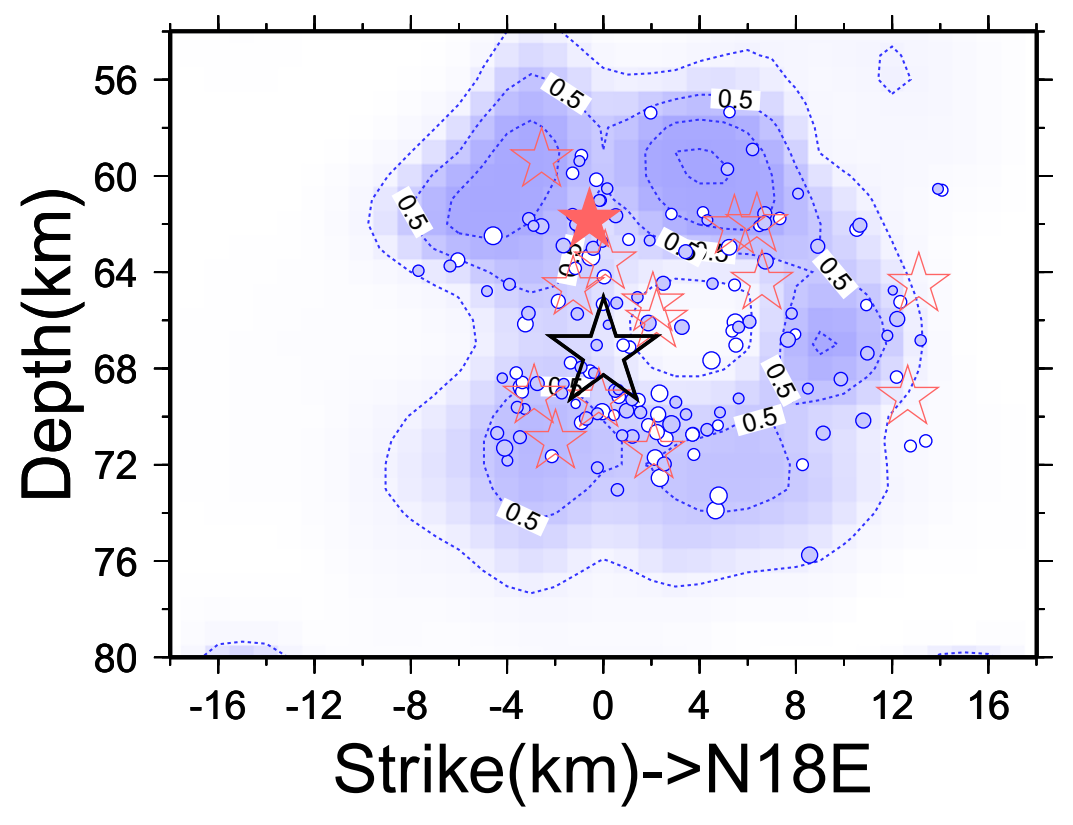

Fig. 7. Slip distribution of the 2003 M7.1 earthquake using another event as EGF. Values normalized by the peak value are shown.

tend of the rupture we obtained is similar to the results in other studies (e.g. Aoi et al., 2003). Slip distribution has two peaks (asperities). Maximum slip, which was calculated from the total moment by the moment tensor inversion of $3 \times 10^{19} \mathrm{Nm}$ and the shear modulus of $7 \times 10^{10} \mathrm{~Pa}$, is about $3 \mathrm{~m}$. One of the asperities (areas where large amount of slip occurred) is elongated along-strike and along the northeastern edge of the rupture area, and the other is below and to the south of the hypocenter. Aftershock activity is low within the areas of the asperities. Figure 6 shows the comparison of synthetic waveforms with observed ones. Observed waveforms are well explained by the synthetic seismograms.

Source inversions using empirical Green's function (EGF) are strongly affected by the selection of the EGF event. To test the stability of the present source process inversion, we adopted a different small event as empirical Green's function and did the same procedure. We selected a smaller event with a magnitude of M4.5 that occurred at 21:12, May 27, 2003. The result by using this different EGF shows almost the same result as in the original case (Fig. 7).

\section{Discussion}

The 2003 off-shore Miyagi earthquake occurred on the upper plane of the double seismic zone. To compare the focal area of the 2003 off-shore Miyagi earthquake and the seismicity around it, we relocated hypocenters of microearthquakes that occurred for the period from 1998 to 2003 around the focal area by using data from the Tohoku University seismograph network. We also adopted the homogeneous station method in this case. Figure 8 shows the relocated hypocenter distribution of these events. Most of events that occurred before the 2003 off-shore Miyagi event align on the upper plane of the double seismic zone. Hypocenter of the 2003 off-shore Miyagi event is located just on the upper plane. In particular, many earthquakes occurred near the hypocenter of the 2003 off-shore Miyagi earthquake. Okada et al. (2003c) studied a M6.4 event, which occurred on the lower plane of the double seismic zone in northeastern Japan, on Dec. 2, 2001. They found that some earthquakes occurred along the fault plane of the 2001 M6.4 event before occurrence of the 2001 event, and suggested that this was evidence of reactivation of pre-existing fault plane as a cause of intermediate-depth events (Kirby et al., 1996). In the case of the 2003 off-shore Miyagi event, it is not so clear that these small events concentrate along the fault plane of the 2003 off-shore Miyagi earthquake which might be the preexisting weak plane.

Figure 9 show the seismicity in the off-shore Miyagi area surrounding the focal area of the 2003 M7.1 event. We also relocated the aftershocks of the 1978 M6.7 intraslab earthquake. This 1978 event is also located on the upper plane of the double seismic zone, and has a similar focal mechanism to the 2003 event. However, the fault plane of the 1978 event seems not to be a steeply dipping plane but a nearly horizontal plane as can be seen from Fig. 9(b). In the case of the 2003 off-shore Miyagi earthquake, the top of the aftershock distribution corresponds with the top of the upper plane seismicity of the double seismic zone, and bottom of the aftershock distribution is significantly deeper than the bottom of the upper plane. This suggests that downdip compressional stress regime would be distributed not only within the subducting oceanic crust (c.f. Matsuzawa et al., 1986) but also in the upper portion of the slab. Before the 2003 off-shore Miyagi earthquakes, some earthquakes occurred near the focal region between the upper plane and the lower plane of the double seismic zone. This feature is characteristic only for the focal region of the 2003 event. Few events occurred between the upper and lower seismic planes in other areas of NE Japan, e.g. along the line b-b'.

Zhang et al. (2003) obtained the high-resolution seismic velocity structure within the subducting slab beneath northeastern Japan by double-difference tomography (Zhang and Thurber, 2003). Their results show that there exist areas of relatively low $P$-wave velocity along the upper and lower 
(a)

(b)
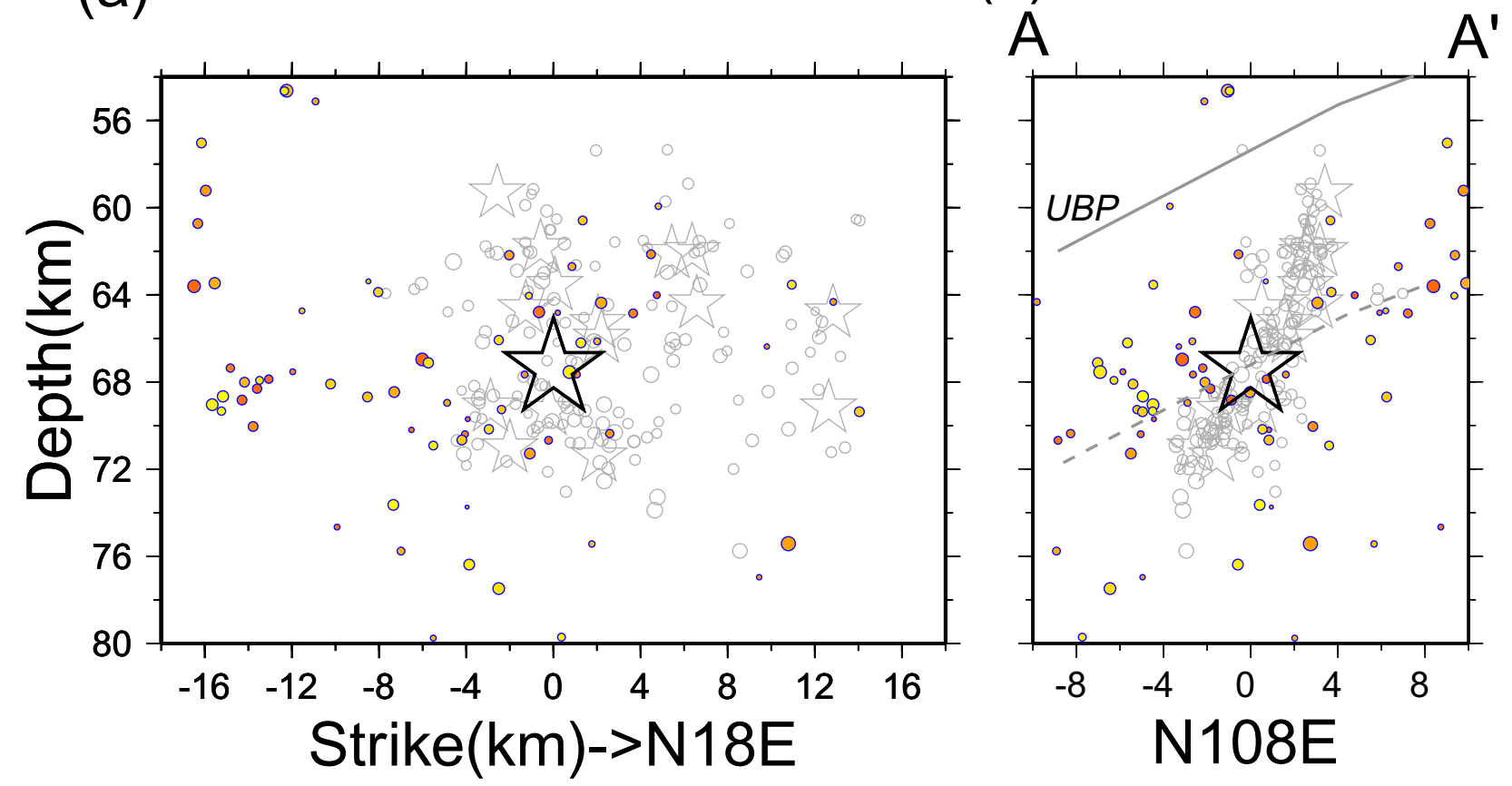

(c)

$141^{\circ} 30^{\prime}$

$142^{\circ} 00^{\prime}$
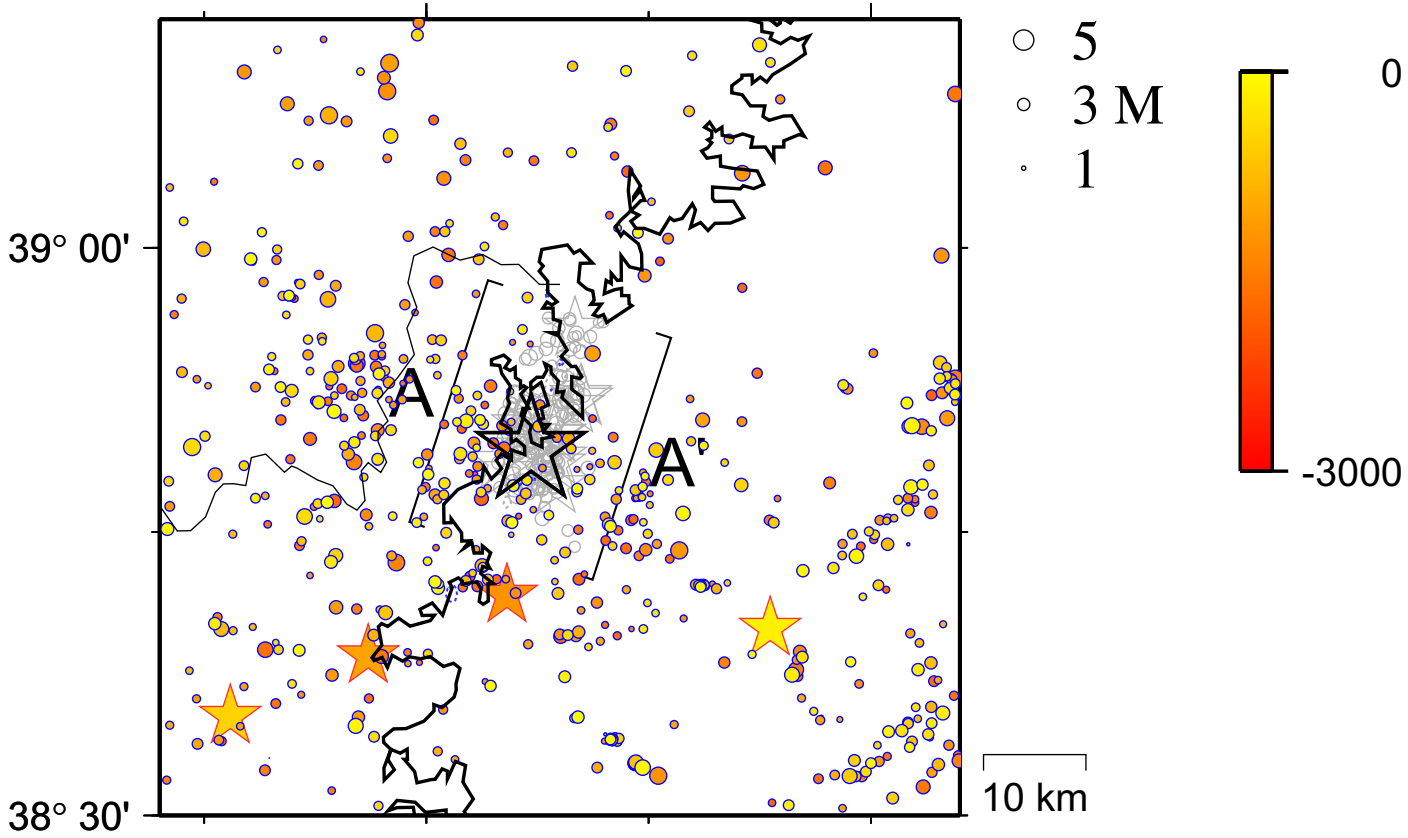

Fig. 8. Background seismicity near the focal area of the 2003 M7.1 event. Relocated hypocenters of earthquakes for the period from 1998 to 2003 are shown. Colors of symbols show the occurrence time in days by the scale on the right. Events with magnitude greater than 4.5 are shown by middle stars. Aftershock distribution shown in Fig. 3 is also shown by gray symbols.

seismic planes. In contrast, there exist areas of relatively high $P$-wave velocity between the upper and lower seismic planes. They interpreted that relatively small amount of water is distributed in this area compared to those in the upper and lower seismic planes. One hypothesis regarding the origin of intermediate-depth earthquakes is dehydration embrittlement (e.g. Kirby et al., 1996). Dehydration increases pore pressure and reduces the effective normal stress, and low effective normal stress eventually causes brittle fracture event at depths of intermediate-depth earthquakes. Small amount of water might be the cause of low seismicity between the upper and lower seismic planes. If there are relatively high amount of hydrated minerals under some conditions in and around the focal area of the 2003 off-shore Miyagi earthquake compared to other areas, earthquakes could occur more frequently in the areas between the upper and lower planes and the rupture could extend into those areas between the upper and lower planes.

Near the 2003 off-shore Miyagi earthquake, an interplate earthquake with magnitude of 6.3 occurred on Nov. 3, 2002 
(a)
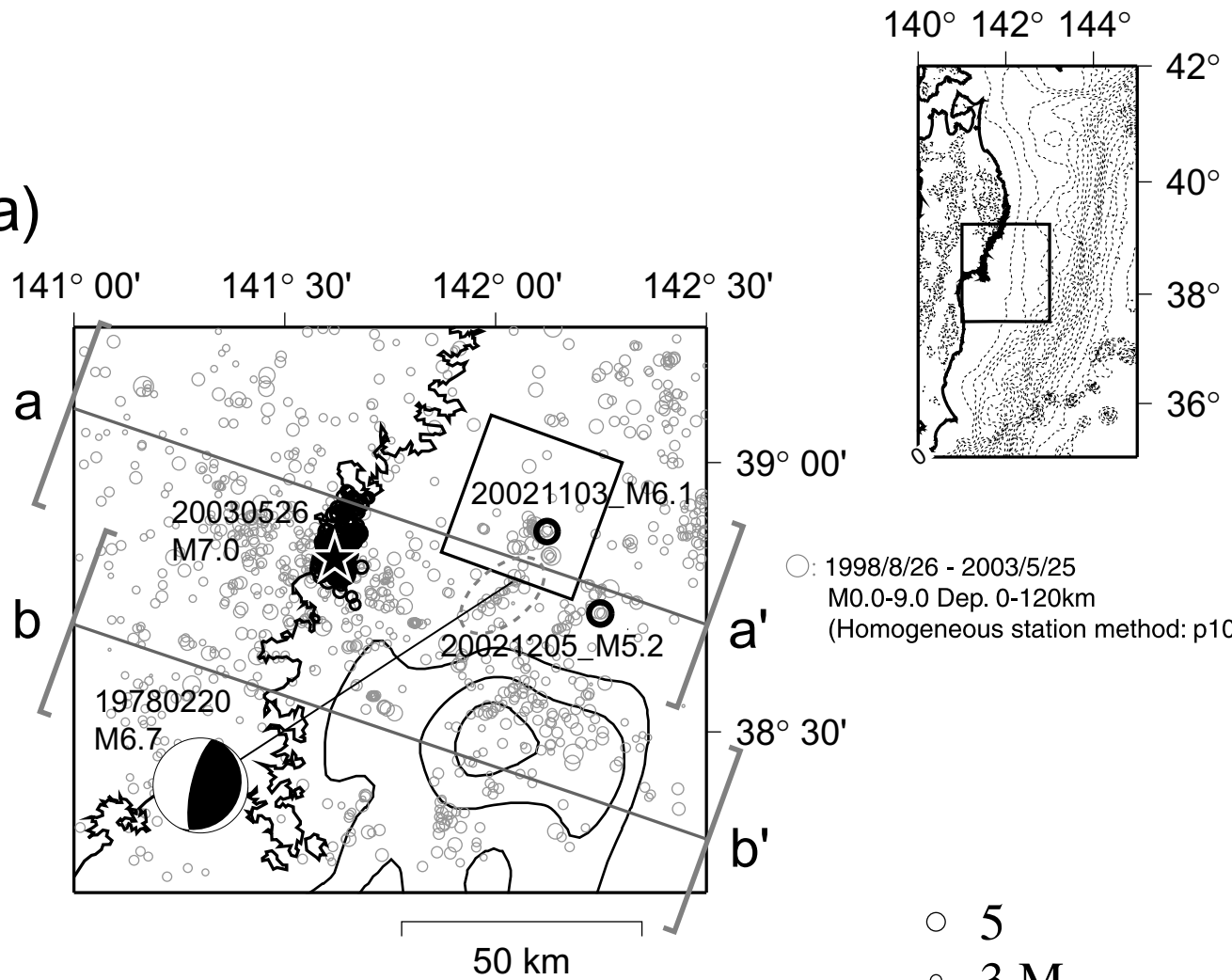

$1998 / 8 / 26-2003 / 5 / 25$

M0.0-9.0 Dep. 0-120km

(Homogeneous station method: p10s5)

(b)

(c)

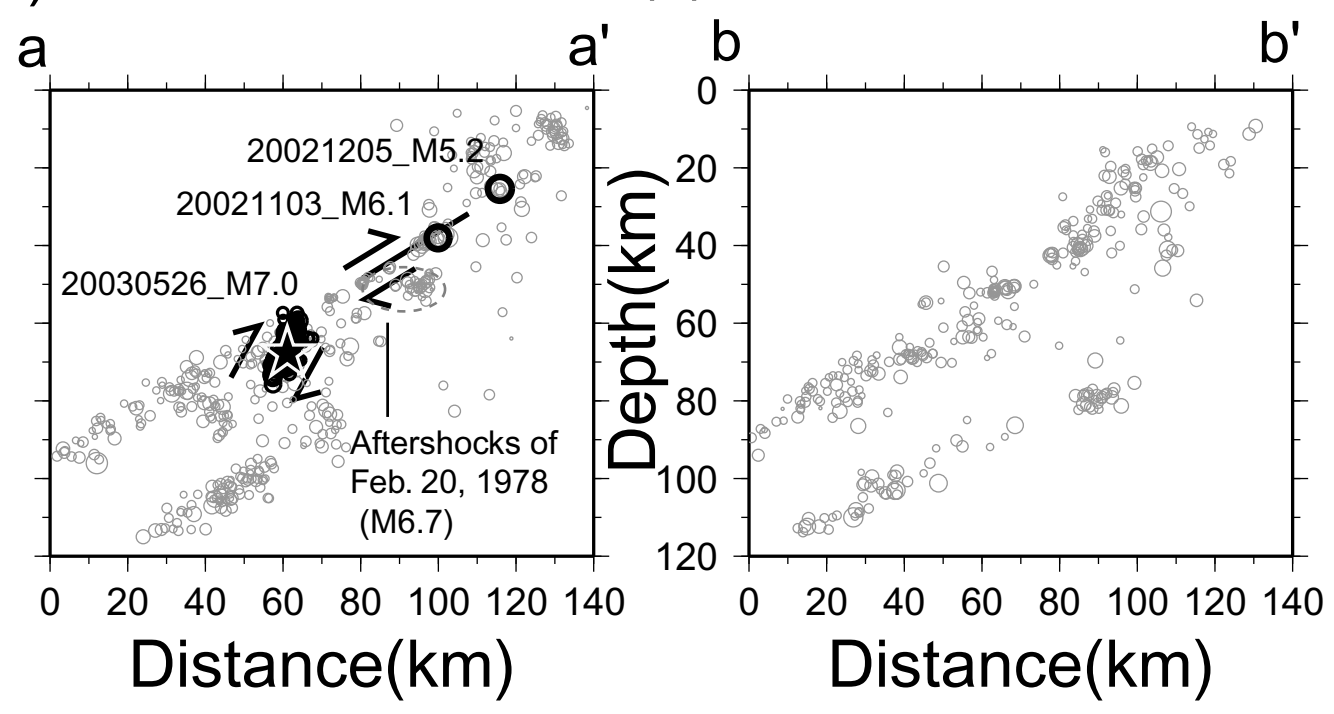

Fig. 9. Seismicity around the focal area of the 2003 off-shore Miyagi earthquake. (a) Epicenter map. (b) Vertical cross section along the line a-a' in (a). (c) Vertical cross section along the line b-b' in (a). Square denotes quasi-static slip area following the Nov. 3, 2002 M6.3 event estimated from GPS observation (Miura et al., 2003). Contour shows the rupture area of the 1978 M7.4 off-shore Miyagi earthquake estimated from waveform inversion (Yamanaka and Kikuchi, 2002). Contour interval is $1 \mathrm{~m}$.

(Okada et al., 2003a). We also relocated this event. This event is located about $50 \mathrm{~km}$ to the east of the 2003 offshore Miyagi earthquake (Fig. 8(a)). GPS observations detected postseismic slip that occurred in a wide area on the plate boundary after this event (Geographical Survey Institute, 2003). Miura et al. (2003) estimated the spatial extent of this postseismic quasi-stable slip following the 2002 M6.3 event. The focal area of the 2003 off-shore Miyagi earthquake is locate right below the plate boundary at the deeper extension of this postseismic slip. In a sense, motion of this quasi-stable slip (reverse fault) may promote the occurrence of the 2003 off-shore Miyagi earthquake (see Fig. 8(b)). Quantitative modeling based on precise hypocenter distribution obtained in this study is necessary to understand the interaction between the interplate and intraslab earthquakes in further studies. 


\section{Conclusions}

We relocated hypocenters of the 2003 M7.1 intra-slab offshore Miyagi earthquake and its aftershocks by the homogeneous station method. Relocated aftershocks are distributed along a steeply dipping plane, which coincides with one of the nodal planes of the moment tensor solution of the main shock. They are located along and below the upper seismic plane of the double seismic zone, within both the subducting oceanic crust and the mantle of the slab. The mainshock is located near the center of the aftershock area, probably near the base of the oceanic crust. The spatial extent of the rupture area estimated from waveform inversion is similar to that of the aftershock area. Areas with large slip (asperities) are distributed along the northeastern edge of the rupture area and on its southwestern portion. Aftershock activity is low within the areas of the asperities. In and around the focal area of the 2003 off-shore Miyagi earthquake, seismic activity occurred in areas between the upper and lower seismic planes of the double seismic zone prior to the 2003 off-shore Miyagi earthquakes. The M6.3 interplate event on Nov. 3, 2002, which occurred near the 2003 off-shore Miyagi event, and its postseismic slip might affect the occurrence of the 2003 off-shore Miyagi event in the slab.

Acknowledgments. We used data from F-net, Kik-net and seismic intensity network of Miyagi prefecture. We are very grateful to the staffs for their effort of observations. Moment tensors were computed using the tdmt-invc package developed by D. Dreger of the Berkeley Seismological Laboratory, and Green's functions were computed using the FKRPROG software developed by C. Saikia with URS Granger, Woodward Clyde Federal Services. We are grateful to Prof. F. Tajima for kind suggestions about moment tensor inversion and fruitful discussions. We thank Dr. N. Umino, Dr. T. Matsuzawa and Dr. D. Zhao for many valuable discussions. We also thank Mr. T. Nakayama for his assistance in moment tensor inversion. We are also grateful to Prof. Y. Honkura, Dr. J. Hardbeck and two anonymous reviewers for the helpful comments.

\section{References}

Aoi, S., H. Sekiguchi, R. Honda, N. Morikawa, T. Kunugi, and H. Fujiwara, Ground motion and rupture process of the 26 May 2003 Off-Miyagi Earthquake obtained from strong motion data of K-NET and KiK-net, Programme and abstracts, the Seismological Society of Japan, 2003, Fall Meeting, A077, 2003.

Ansel, J. H. and E. G. C. Smith, Detailed structure of a mantle seismic zone using the Homogeneous Station Method, Nature, 253, 518-520, 1975.

Flecther, J. B. and P. Spudich, Rupture characteristics of the three M4.7 (1992-1994) Parkfield earthquakes, J. Geophys. Res., 103, 835-854, 1998.

Geographical Survey Institute, Crustal movements in the Tohoku district, Report of the Meeting of the Coordinating Committee for Earthquake Prediction, 70, 2003 (in press).
Hartzell, S., Earthquake aftershocks as Green's functions, Geophysical Research Letters, 5, 1-4, 1978.

Hartzell, S. and T. Heaton, Inversion of strong ground motion and teleseismic waveform data for the fault rupture history of the 1979 Imperial Valley, California, earthquake, Bulletin of Seismological Society of America, 73, 1553-1583, 1983.

Hasegawa, A., N. Umino, and A. Takagi, Double-planed structure of the deep seismic zone in the northeastern Japan arc, Tectonophys., 47, 43$58,1978$.

Kirby, S. H., E. Engdahl, and R. Denlinger, Intra slab earthquakes and arc volcanism: Dual physical expressions of crustal and uppermost mantle metamorphism in subducting slabs, in Subduction: Top to bottom, edited by G. E. Bebout et al., American Geophysical Union Geophysical Monograph, 1996.

Matsuzawa, T., N. Umino, A. Hasegawa, and A. Takagi, Upper mantle velocity structure estimated from $P S$-converted wave beneath the northeastern Japan arc, Geophysical J. R. astr. Soc., 86, 767-787, 1986.

Miura, S., K. Suwa, Y. Sato, A. Tachibana, and A. Hasegawa, Slow slip events on the plate boundary off Miyagi and Fukushima detected by GPS and strain measurements, Abstracts for the 2003 Joint Meeting of Earth and Planetary Science, D007-D011, 2003.

Mori, J. and S. Hartzell, Source inversion of the 1988 Upland, California, earthquake: Determination of a fault plane for a small event, Bulletin of Seismological Society of America, 80, 507-518, 1990.

Okada, T., N. Umino, Y. Ito, T. Matsuzawa, A. Hasegawa, and M. Kamiyama, Source processes of 15 September 1998 M5.0 Sendai, NE Japan, earthquake and its M3.8 foreshock by waveform inversion, Bulletin of Seismological Society of America, 91, 1607-1618, 2001a.

Okada, T., T. Yamashita, T. Nakayama, T. Matsuzawa, A. Hasegawa, and F. Tajima, Determination of moment tensors using Tohoku University's broad-band seismic network, Prog. Abst. for Fall Meet. Seism. Soc. Japan, P105, 2001b (in Japanese).

Okada, T., T. Matsuzawa, and A. Hasegawa, Repeating ruptures of asperities along the plate boundary east off northeastern Japan, Abstracts for the 2003 IUGG General Assembly, JSS01/30A/D-060, 2003 a.

Okada, T., T. Matsuzawa, and A. Hasegawa, Comparison of source areas of M4.8+/- 0.1 repeating earthquakes off Kamaishi, NE Japan-Are asperities persistent features?, Earth and Planetary Science Letters, $\mathbf{2 1 3}$ 361-374, 2003b.

Okada, T., N. Umino, and A. Hasegawa, Source process of M6.4 intermediate-depth earthquake that occurred in the lower plane of the double seismic zone beneath northeastern Japan, J. Seism., 2003c (in press).

Yamanaka, Y. and M. Kikuchi, Characteristic behavior of asperities, Abstracts for the 2002 Joint Meeting of Earth and Planetary Science, J076J002, 2002.

Zhang, H. and C. Thurber, Double-Difference Tomography: the method and its application to the Hayward Fault,California, Bulletin of Seismological Society of America, 93, 1875-1889, 2003.

Zhang, H., C. Thurber, D. Shelly, S. Ide, G. Beroza, and A. Hasegawa, Subducting slab structure beneath northern Honshu, Japan, revealed by Double-Difference tomography, Geology, 2003 (in press).

Zhao, D., T. Matsuzawa, and A. Hasegawa, Morphology of the subducting slab boundary in the northeastern Japan arc, Phys. Earth Planet. Inter. 102, 89-104, 1997.

T. Okada (e-mail: okada@aob.geophys.tohoku.ac.jp) and A. Hasegawa 